Grand Valley State University

ScholarWorks@GVSU

2012

\title{
The Role of Age and Sex in Symptoms, Neurocognitive Performance, and Postural Stability in Athletes After Concussion
}

Tracey Covassin

Michigan State University, covassin@msu.edu

R. J. Elbin

University of Pittsburgh - Main Campus

William Harris

Michigan State University

Tonya Parker

Grand Valley State University, parkert@gvsu.edu

Anthony Kontos

University of Pittsburgh - Main Campus

Follow this and additional works at: https://scholarworks.gvsu.edu/mov_articles

\section{ScholarWorks Citation}

Covassin, Tracey; Elbin, R. J.; Harris, William; Parker, Tonya; and Kontos, Anthony, "The Role of Age and Sex in Symptoms, Neurocognitive Performance, and Postural Stability in Athletes After Concussion" (2012). Peer Reviewed Articles. 1.

https://scholarworks.gvsu.edu/mov_articles/1

This Article is brought to you for free and open access by the Movement Science Department at ScholarWorks@GVSU. It has been accepted for inclusion in Peer Reviewed Articles by an authorized administrator of ScholarWorks@GVSU. For more information, please contact scholarworks@gvsu.edu. 


\title{
The Role of Age and Sex in Symptoms, Neurocognitive Performance, and Postural Stability in Athletes After Concussion
}

\author{
Tracey Covassin, ${ }^{\star \dagger} \mathrm{PhD}, \mathrm{ATC}$, R.J. Elbin, ${ }^{\ddagger} \mathrm{PhD}$, William Harris, ${ }^{\dagger} \mathrm{MS}$, Tonya Parker, ${ }^{\S} \mathrm{PhD}, \mathrm{AT}, \mathrm{ATC}$, \\ and Anthony Kontos, ${ }^{\ddagger} \mathrm{PhD}$ \\ Investigation performed at Michigan State University, East Lansing, Michigan
}

\begin{abstract}
Background: Researchers have begun to focus on age and sex differences in concussion outcomes. Results suggest that younger athletes and female athletes may take longer to recover from a concussion. However, little is known about the interactive effects of age and sex on symptoms, neurocognitive testing (NCT), and postural stability.

Hypothesis/Purpose: The purpose of the study was to examine sex and age differences in symptoms, NCT, and postural stability following concussion. We hypothesized that high school and female athletes would have worse symptoms, NCT, and postural stability than college and male athletes, respectively.
\end{abstract}

Study Design: Cohort study; Level of evidence, 2.

Methods: A total of 296 concussed athletes from a multistate, 2-year study were enrolled in this study. Participants completed the Immediate Post-Concussion Assessment and Cognitive Test (ImPACT) and Post-Concussion Symptom Scale (PCSS) at baseline and again at 2, 7, and 14 days after concussion. Participants completed the Balance Error Scoring System (BESS) at 1,2 , and 3 days after concussion.

Results: Female athletes performed worse than male athletes on visual memory (mean, $65.1 \%$ and $70.1 \%$, respectively; $P=.049$ ) and reported more symptoms (mean, 14.4 and 10.1, respectively) after concussion $(P=.035)$. High school athletes performed worse than college athletes on verbal (mean, $78.8 \%$ and $82.7 \%$, respectively; $P=.001$ ) and visual (mean, $65.8 \%$ and $69.4 \%$, respectively; $P=$ .01) memory. High school athletes were still impaired on verbal memory 7 days after concussion compared with collegiate athletes $(P=.001)$. High school male athletes scored worse on the BESS than college male athletes (mean, 18.8 and 13.0, respectively; $P=$ .001). College female athletes scored worse on the BESS than high school female athletes (mean, 21.1 and 16.9, respectively; $P=.001$ ).

Conclusion: The results of the current study supported age differences in memory and sex differences in memory and symptoms and an interaction between age and sex on postural stability after concussion that warrant consideration from clinicians and researchers when interpreting symptoms, specific components of NCT, and postural stability tests. Future research should develop and assess interventions tailored to age and sex differences and include younger ( $<14$ years) participants.

Keywords: concussion; mTBI; neurocognitive testing; symptoms; postural stability; age; sex

Researchers estimate that between 1.6 and 3.8 million sport-related concussions occur each year in the United

\footnotetext{
*Address correspondence to Tracey Covassin, Michigan State University, Department of Kinesiology, 105 IM Sports Circle, East Lansing, MI 48824 (e-mail: covassin@msu.edu).

${ }^{\dagger}$ Department of Kinesiology, Michigan State University, East Lansing, Michigan.

₹University of Pittsburgh Medical Center Sports Medicine Concussion Program, Department of Orthopaedic Surgery, University of Pittsburgh School of Medicine, Pittsburgh, Pennsylvania.

§Department of Movement Science, Grand Valley State University, Allendale, Michigan.

One or more of the authors has declared the following potential conflict of interest or source of funding: The National Operating Committee on Standards for Athletic Equipment (NOCSAE) funded this study.
}

The American Journal of Sports Medicine, Vol. 40, No. 6 DOI: $10.1177 / 0363546512444554$

(C) 2012 The Author(s)
States. ${ }^{27}$ Between 2001 and 2005, over 150,000 sportrelated concussions occurred among youth aged 14 to 19 years. ${ }^{3}$ However, the actual number of sport-related concussions in this age group is likely much higher, as the preceding number reflects only concussions that involved visits to emergency departments. Recently, there has been a focus on sex differences in concussion and related outcomes. Researchers suggest that women are at higher risk for concussion than men ${ }^{11}$ and may take longer to recover from a concussion than men. ${ }^{7,10}$ However, little is known about the interactive effects of age and sex on concussion outcomes including symptoms, neurocognitive testing (NCT), and postural stability.

Current concussion consensus statements recommend that the management of sport-related concussion take a multifaceted approach that includes symptom inventories, balance assessments, and computerized NCT. ${ }^{33}$ Symptom inventories (eg, Post-Concussion Symptom Scale 
[PCSS]) allow athletes to self-report their current symptoms along with severity ratings for each endorsed symptom. In addition, computerized neurocognitive tests (eg, Immediate Post-Concussion Assessment and Cognitive Test [ImPACT]) and balance assessments (eg, Balance Error Scoring System [BESS]) help to objectively quantify the cognitive impairment and postural stability deficits that often accompany concussive injury.

Ideally, these measures are administrated at baseline to healthy athletes and repeated at postinjury intervals to provide a more individualized and objective approach to assessing and managing sport-related concussion. ${ }^{43}$ The advent of baseline NCT and postural stability testing has provided researchers with measures to quantify the impairments that accompany concussion and allows for direct preinjury to postinjury intraindividual comparisons of these impairments across age groups and sex. ${ }^{8,10}$

With regard to neurocognitive effects, researchers have reported that high school athletes take longer to recover from a concussion than do collegiate athletes. ${ }^{19,31,34}$ Specifically, high school athletes have been found to demonstrate significant memory impairment up to 7 to 14 days after concussion $^{19,31}$ and reaction time impairments up to 14 to 21 days after concussion. ${ }^{9,31}$ Iverson et $\mathrm{al}^{24}$ reported that $37 \%$ of concussed high school athletes were still clinically impaired on 2 or more neurocognitive measures (verbal memory, visual memory, reaction time, processing speed) at 10 days after concussion. In contrast, neurocognitive impairment in sustained auditory attention and visuomotor processing speed was resolved within 5 days of concussion in a sample of college athletes. ${ }^{30}$ Similarly, a recent study by Echemendia and colleagues ${ }^{15}$ did not report any neurocognitive impairments past 7 days after injury in college athletes. These results suggest that college athletes generally experience a rapid resolution of cognitive impairments after concussion. Some researchers have concluded that the anatomic, behavioral, and physical differences between the adolescent and adult brain, together with the purported susceptibility of the adolescent brain to long-term impairments from head trauma, may explain the reported age differences. ${ }^{32}$

In addition to age, differences in neurocognitive recovery after concussion have also been examined between male and female athletes. These investigations follow established findings on sex differences for verbal memory, perceptual motor speed, accuracy, and visuospatial tasks in the general neurocognitive literature. ${ }^{4,26}$ Covassin et $\mathrm{al}^{10}$ reported that after concussion, female collegiate athletes demonstrated significantly poorer visual memory performance than male athletes. Similarly, Broshek and colleagues $^{5}$ reported that concussed female athletes were 1.7 times more likely to be cognitively impaired than male athletes. Other studies have reported that concussed female athletes had slower reaction times and more postconcussion symptoms than concussed male athletes. ${ }^{5,7}$ However, the Colvin et $\mathrm{al}^{7}$ study was retrospective and failed to control for time since injury when comparing neurocognitive scores between sexes. Sex differences in cognitive function after a concussion may be caused by hormonal differences, weak musculature, neuroanatomic differences, or cerebrovascular organization. ${ }^{13,17,18,41,42}$ In addition, there has long been a debate in the literature as to whether estrogen has a detrimental or a protective effect on concussion outcome.

Researchers have also investigated sex differences on self-reported concussion symptoms assessed before and after injury. Some studies have reported that women endorse an increased number of symptoms at baseline compared with men, ${ }^{12,40}$ while other researchers have reported that baseline symptom reports did not differ by sex. ${ }^{12}$ In contrast, sex differences on symptom reports seem to be more consistent and pronounced after concussion, with female athletes endorsing a greater number of postconcussion symptoms compared with male athletes. Recent reports have not supported sex differences in recovery time based on postconcussion symptoms. ${ }^{6}$ However, the aforementioned study $^{6}$ used athletes with moderate or severe concussions who reported 3 or more previous concussions and had symptoms lasting well beyond $(>90$ days) the typical 7 to 10 days. Thus, continued study is warranted to determine if sex differences exist on symptom inventories used for concussion management. With regard to age, researchers have reported no significant differences on baseline symptom reports between high school or college-age athletes. ${ }^{29}$ However, considering the prolonged neurocognitive recovery times reported in high school athletes compared with collegiate athletes, ${ }^{19}$ it would seem an examination of potential age differences in concussion symptom reporting is also warranted.

In conjunction with computerized NCT and symptom inventories, balance assessments provide important information on the postural stability of the concussed athlete. ${ }^{21}$ The BESS was designed for clinicians as a less sophisticated but cost-effective measure for objective postural stability testing. ${ }^{36}$ The BESS has been shown to measure balance deficits in concussed athletes up to 3 days after injury. ${ }^{22,35,36}$ Researchers have reported sex differences in children performing a single-legged upright standing position with eyes open and closed. ${ }^{28}$ Specifically, female participants performed better on postural stability than male participants did. ${ }^{28}$ However, there has been a lack of research investigating differences on balance assessments between male and female and high school and collegiate concussed athletes. Therefore, studies examining age and sex differences on balance assessments would inform the sports medicine practitioner of any postural deficits during the acute phase of concussion management.

The purpose of the present study was to examine sex and age differences in postconcussion symptom reports, NCT performance, and postural stability after concussion. It was hypothesized that concussed high school athletes would exhibit greater total concussion symptoms, neurocognitive impairments, and postural instabilities compared with concussed collegiate athletes. It was also expected that concussed female athletes would exhibit prolonged neurocognitive impairments, greater total concussion symptoms, and increased balance problems when compared with concussed male athletes. Given the lack of support in the literature, no hypotheses were proposed for the interactive effects of age and sex on the above concussion outcomes. 


\section{MATERIALS AND METHODS}

\section{Research Design}

A prospective cohort design was used to compare baseline concussion symptoms and neurocognitive function to postconcussion symptoms and neurocognitive function. In addition, a repeated-measures posttest-only design was used to examine performance on the BESS. The independent variables were age (high school athlete, college athlete), sex (male, female), and time (baseline, 2 days, 7 days, 14 days). The dependent variables were the performance on the BESS and neurocognitive test scores (verbal and visual memory, processing speed, and reaction time) as measured by the ImPACT neurocognitive battery.

\section{Participants}

A total of 296 (203 male and 93 female; 203 high school and 93 college) athletes from an ongoing sport concussion surveillance study in California, Michigan, Louisiana, and Tennessee who sustained a concussion during the 2008-2009 and 2009-2010 academic years were enrolled in the study. Approximately 2000 athletes were tested at baseline to obtain the concussion sample. Inclusion criteria included age 14 to 25 years and athletes who sustained a sportrelated concussion that was diagnosed by a sports medicine professional. Exclusion criteria included a history of treatment for substance abuse, psychiatric disorder, special education, years repeated in school, and speech problems. After applying exclusion criteria and not including any athletes without a baseline ImPACT score (28 athletes), 222 (157 male and 65 female; 150 high school and 72 college) athletes were included in the postconcussion analyses.

\section{Operational Definition of Concussion}

Concussion was operationally defined as "a complex pathophysiological process affecting the brain, induced by traumatic biomechanical forces" ${ }^{\prime 3}$ and was required to meet the following criteria: (1) presence of on-field signs (eg, posttraumatic amnesia, loss of consciousness) and symptoms (eg, dizziness, headache) as determined by a sports medicine professional trained to identify concussions, (2) decrease from baseline levels in at least one postconcussion neurocognitive score determined by reliable change estimates, ${ }^{24}$ and (3) increase from baseline levels in postconcussion symptoms determined by reliable change estimates.

\section{ImPACT}

To assess neurocognitive function, the online version of the ImPACT neurocognitive battery was used for this study. The ImPACT takes approximately 25 minutes to complete and has 5 different test versions to minimize and control for practice effects. The ImPACT neurocognitive battery is made up of 3 general sections that include demographics, the PCSS, and neurocognitive modules. Verbal memory, visual memory, visual processing speed, and reaction time composite scores are provided by the ImPACT. Test-retest reliability, validity, and specificity/sensitivity data for the ImPACT are reported elsewhere. ${ }^{16,38,39}$ In addition, Reliable Change Index (verbal memory $\geq 9$, visual memory $\geq 14$, motor processing speed $\geq 5$, reaction time $>0.06$, total symptom score $\geq 10$ ) were used to determine when an athlete had recovered from his or her concussion.

\section{BESS}

The BESS is a balance assessment that is designed to evaluate static and dynamic postural stability after concussion. The BESS involves a trained observer who assesses total errors in balance while athletes perform each of 6 timed test conditions with eyes closed and feet on the floor or on a foam pad. A complete description of the 6 test conditions of the BESS is published elsewhere. ${ }^{22}$ A higher score on the BESS indicates greater numbers of errors and thus worse postural stability. The BESS has significant correlations with force platform sway measures, with intratester reliability coefficients ranging from .87 to $.97 .^{36}$

\section{Procedures}

Preseason Baseline Evaluation. The study was approved by each participating institution's university institutional review board before data collection. Athletes over the age of 18 years provided informed written consent, and all minors (under 18 years) were required to submit parental written consent and assent before data collection. Athletes reported in groups of no more than 10 at a time to their own institution's designated ImPACT computer laboratory for baseline testing. Athletes were administered the ImPACT neurocognitive battery that includes the PCSS on a computer (approximately 25 minutes). Trained members of the sports medicine staff (eg, certified athletic trainer [ATC]) or research team administered the baseline measures. Unfortunately, because of the large sample size of baseline scores (over 2000), we were unable to administer the baseline BESS.

Postconcussion Evaluation. All ATCs and physicians at the participating institutions were instructed to use the Concussion in Sport Group guidelines to determine if an athlete sustained a concussion. ${ }^{33}$ All concussed athletes were readministered the ImPACT neurocognitive battery at 2,7 , and 14 days after concussion by the graduate research assistants and/or their respective athletic trainer. Athletes were also administered the BESS at day 1,2, and 3 after concussion. All return-to-play decisions were determined by each concussed athlete's respective institution's sports medicine staff, who all followed the Concussion in Sport Group guidelines. ${ }^{2,33}$ The return-to-play recommendations made by the Concussion in Sport Group are centered on a medically supervised stepwise process. The recommended return-to-play stepwise process following a concussion includes the following: (1) no activity and complete rest until asymptomatic, (2) light aerobic exercise such as walking or stationary cycling but no resistance training, (3) sport-specific exercise and progressive 
TABLE 1

Demographic Information for Male and Female High School $(\mathrm{n}=150)$ and Collegiate $(\mathrm{n}=72)$ Athletes ${ }^{a}$

\begin{tabular}{|c|c|c|c|c|}
\hline & \multicolumn{2}{|c|}{ High School } & \multicolumn{2}{|c|}{ College } \\
\hline & Male & Female & Male & Female \\
\hline Age, $y$ & $15.6 \pm 1.19$ & $15.43 \pm 1.22$ & $19.52 \pm 1.08$ & $18.94 \pm 1.55$ \\
\hline Height, inches & $69.81 \pm 3.00$ & $65.55 \pm 2.82$ & $72.25 \pm 2.86$ & $67.29 \pm 3.25$ \\
\hline Weight, lb & $168.64 \pm 34.09$ & $140.67 \pm 22.90$ & $206.42 \pm 34.40$ & $146.83 \pm 19.94$ \\
\hline
\end{tabular}

${ }^{a}$ Values expressed as mean \pm standard deviation.

addition of resistance training, (4) noncontact training drills, (5) full contact training after medical clearance, and (6) game play. Trained members of the sports medicine staff (eg, ATC) or research team administered the postconcussion measures.

Analyses of Hypotheses. The data were analyzed using descriptive and inferential statistics. A series of 4 (time: baseline, 2 days, 7 days, and 14 days $) \times 2($ sex $) \times 2$ (age: high school and college) repeated-measures analysis of variance (RM ANOVA) for concussion symptoms and ImPACT composite scores (verbal/visual memory, processing speed, reaction time) were used to evaluate the hypotheses. In addition, separate 2 (sex) $\times 2$ (age) $\times 3$ (time) RM ANOVAs were performed on the BESS scores. Post hoc mean comparisons were performed using the Tukey honestly significant difference test. All data were analyzed using SPSS 18.0 (SPSS Inc, Chicago, Illinois). Statistical significance for all analyses was set at $P<.05$, and a Bonferroni correction was used to control for multiple comparisons.

\section{RESULTS}

\section{Concussion Demographic Data}

A total of 222 (157 male and 65 female; 150 in high school and 72 in college) athletes were included in the postconcussion analyses. The majority of concussions occurred in football ( $\mathrm{n}=121)$, followed by women's soccer $(\mathrm{n}=30)$, men's soccer ( $\mathrm{n}=12$ ), women's volleyball $(\mathrm{n}=12)$, women's basketball $(\mathrm{n}=11)$, wrestling $(\mathrm{n}=8)$, men's basketball $(\mathrm{n}=8)$, women's ice hockey $(\mathrm{n}=5)$, softball $(\mathrm{n}=4)$, rugby $(\mathrm{n}=4)$, women's crew $(\mathrm{n}=2)$, baseball $(\mathrm{n}=2)$, cheerleading $(\mathrm{n}=$ $1)$, men's ice hockey $(\mathrm{n}=1)$, and men's lacrosse $(\mathrm{n}=1)$. Nine athletes had a second concussion during the 2-year study. The overall concussion history for the sample was $1.08 \pm 1.29$ (mean \pm standard deviation) previous concussions. A series of independent $t$ tests revealed no significant differences in concussion history among male $(.98 \pm 1.06)$ and female $(.97 \pm 1.20)$ athletes or high school $(.8 \pm .88)$ and collegiate $(1.19 \pm 1.35)$ age groups. Demographic information for age, height, and weight can be found in Table 1.

\section{BESS}

A 2 (sex) $\times 2$ (age) $\times 3$ (time) RM ANOVA was performed for BESS scores and yielded a significant within-subjects main effect for time (Wilks $\lambda=.621, \mathrm{~F}_{2,110}=33.54, P=$

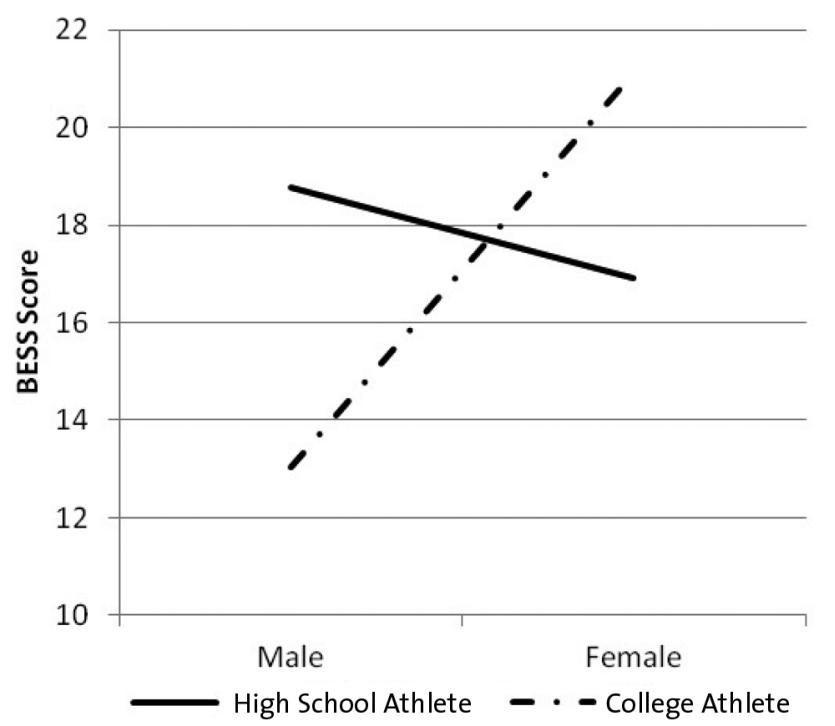

Figure 1. Between-groups sex and age interaction for the Balance Error Scoring System (BESS).

$\left..000, \eta^{2}=.38\right)$ and a between-subjects interaction for sex and age $\left(\mathrm{F}_{1,111}=7.29, P=.008, \eta^{2}=.062\right)$. Specifically, high school male athletes scored slightly worse than high school female athletes on the BESS, whereas college female athletes scored significantly worse on the BESS than male college athletes (Figure 1). Athletes' BESS scores were highest at 1 day after concussion and were significantly lower from 1 day to 2 days $(P=.001)$, from 2 days to 3 days $(P=.001)$, and from 1 day to 3 days $(P=.001)$ after concussion. There were no significant main effects for age $\left(\mathrm{F}_{1,111}=.176, P=.676, \eta^{2}=.002\right)$ or $\operatorname{sex}\left(\mathrm{F}_{1,111}=\right.$ 2.82, $\left.P=.096, \eta^{2}=.025\right)$ on the BESS. The means and standard deviations for the BESS are presented in Table 2.

\section{Postconcussion Symptoms}

The results of the RM ANOVA demonstrated a significant within-subjects effect for time on concussion symptoms (Wilks $\lambda=.470, \mathrm{~F}_{3,116}=43.58, P=.000, \eta^{2}=.530$ ), with athletes exhibiting significantly more symptoms 7 days after concussion compared with baseline $(P=.011)$. Athletes returned to baseline concussion symptom scores by 14 days after injury $(P=.859)$. The results also supported 
TABLE 2

Means and Standard Deviations (SDs) for the Balance Error Scoring System (BESS) for Concussed Male and Female High School $(n=150)$ and Collegiate $(n=72)$ Athletes

\begin{tabular}{|c|c|c|c|c|c|c|}
\hline & \multicolumn{2}{|c|}{1 Day } & \multicolumn{2}{|c|}{2 Days } & \multicolumn{2}{|c|}{3 Days } \\
\hline & Mean & SD & Mean & SD & Mean & SD \\
\hline \multicolumn{7}{|l|}{ Age group } \\
\hline High school & 22.22 & 8.87 & 18.49 & 8.30 & 14.71 & 7.61 \\
\hline College & 19.43 & 10.05 & 16.97 & 8.74 & 14.48 & 9.09 \\
\hline \multicolumn{7}{|l|}{ Sex } \\
\hline Male & 21.41 & 9.63 & 17.78 & 8.92 & 14.17 & 7.76 \\
\hline Female & 21.75 & 7.95 & 19.11 & 6.99 & 16.41 & 8.57 \\
\hline Total & 21.50 & 9.22 & $18.10^{a}$ & 8.48 & $14.68^{a, b}$ & 7.97 \\
\hline
\end{tabular}

${ }^{a}$ Significantly different than day $1(P \leq .05)$.

${ }^{b}$ Significantly different than day $2(P \leq .05)$.

TABLE 3

Means and Standard Deviations (SDs) for Total Postconcussion Symptoms for Concussed Male and Female High School $(n=150)$ and Collegiate $(n=72)$ Athletes

\begin{tabular}{|c|c|c|c|c|c|c|c|c|}
\hline & \multicolumn{2}{|c|}{ Baseline } & \multicolumn{2}{|c|}{2 Days } & \multicolumn{2}{|c|}{7 Days } & \multicolumn{2}{|c|}{14 Days } \\
\hline & Mean & SD & Mean & SD & Mean & SD & Mean & $\mathrm{SD}$ \\
\hline \multicolumn{9}{|l|}{ Age group } \\
\hline High school & 6.29 & 7.23 & 26.82 & 19.75 & 11.18 & 14.69 & 3.84 & 7.28 \\
\hline College & 4.59 & 8.62 & 26.28 & 20.83 & 9.90 & 14.85 & 4.92 & 9.56 \\
\hline \multicolumn{9}{|l|}{ Sex } \\
\hline Male & 5.38 & 7.49 & 25.01 & 19.29 & 9.34 & 12.92 & 3.31 & 6.69 \\
\hline Female $^{a}$ & 6.59 & 8.22 & 30.41 & 21.38 & 14.05 & 17.88 & 6.22 & 10.37 \\
\hline Total & 5.75 & 7.71 & $26.65^{b}$ & 20.19 & $10.77^{b}$ & 14.69 & $4.92^{c, d}$ & 9.56 \\
\hline
\end{tabular}

${ }^{a}$ Significantly higher than male athletes $(P \leq .05)$.

${ }^{b}$ Significantly higher than baseline $(P \leq .05)$.

${ }^{c}$ Significantly lower than 2 days $(P \leq .05)$.

${ }^{d}$ Significantly lower than 7 days $(P \leq .05)$.

a between-sex difference for concussion symptoms $\left(\mathrm{F}_{1,118}=\right.$ $4.525, P=.035, \eta^{2}=.037$ ), with female athletes reporting more symptoms than male athletes when all time points were considered (Table 3 ). There were no significant differences for age $\left(\mathrm{F}_{1,118}=.956, P=.330, \eta^{2}=.008\right)$ or the interaction between age and sex $\left(\mathrm{F}_{1,118}=.042, P=.839, \eta^{2}=\right.$ .001) on concussion symptoms.

\section{Neurocognitive Performance and Age Differences}

We performed a series of $2($ sex $) \times 2$ (age) $\times 4$ (time) RM ANOVAs for each ImPACT composite score. The results supported a significant within-subjects main effect for time (Wilks $\lambda=.828, \mathrm{~F}_{3,116}=8.003, P=.001, \eta^{2}=.171$ ) on verbal memory, with athletes being impaired at 2 days after concussion $(P=.001)$ but recovering by 7 days after concussion $(P=.962)$ (Table 4$)$ when compared with baseline scores. In addition, there was a significant within-subjects interaction for time and age (Wilks $\lambda=.888, \mathrm{~F}_{3,116}=$ 4.83, $P=.003, \eta^{2}=.112$ ), with high school athletes demonstrating worse verbal memory performance than collegiate athletes at 2 days $(P=.001)$ and 7 days $(P=.001)$ after concussion (Figure 2). There was no significant main effect for age between high school and collegiate athletes on verbal memory $\left(\mathrm{F}_{1,118}=3.49, P=.064, \eta^{2}=.029\right)$.

Results also revealed a significant within-subjects main effect for time (Wilks $\lambda=.717, \mathrm{~F}_{3,116}=15.228, P=.000, \eta^{2}=$ .283 ) on visual memory (Table 5). Athletes were significantly impaired on visual memory at 2 days $(P=.000)$ and 7 days $(P=.000)$ after concussion; however, they returned back to baseline scores by 14 days after injury $(P=.749)$. A significant within-subjects interaction for time and age was also found for visual memory (Wilks $\lambda=.91, \mathrm{~F}_{3,116}=3.64, P=.02, \eta^{2}=.09$ ), with high school athletes demonstrating worse visual memory performance than collegiate athletes at 2 days after concussion $(P=.01)$ (Figure 3). There were no significant main effects for age between high school and collegiate athletes on visual memory $\left(\mathrm{F}_{1,118}=2.054, P=.154, \eta^{2}=.017\right)$.

There was a significant within-subjects main effect for time on reaction time (Wilks $\lambda=.790, \mathrm{~F}_{3,115}=$ $10.19, P=.001, \eta^{2}=.210$ ) and motor processing speed 
TABLE 4

Means and Standard Deviations (SDs) for Verbal Memory Performance for Concussed Male and Female High School $(\mathrm{n}=150)$ and Collegiate $(\mathrm{n}=72)$ Athletes

\begin{tabular}{|c|c|c|c|c|c|c|c|c|}
\hline & \multicolumn{2}{|c|}{ Baseline } & \multicolumn{2}{|c|}{2 Days } & \multicolumn{2}{|c|}{7 Days } & \multicolumn{2}{|c|}{14 Days } \\
\hline & Mean & $\mathrm{SD}$ & Mean & $\mathrm{SD}$ & Mean & $\mathrm{SD}$ & Mean & $\mathrm{SD}$ \\
\hline \multicolumn{9}{|l|}{ Age group } \\
\hline High school & 82.96 & 10.38 & 69.93 & 16.82 & 77.61 & 16.02 & 83.55 & 12.52 \\
\hline College & 83.39 & 9.26 & $80.89^{a}$ & 12.36 & $83.89^{a}$ & 13.01 & 82.26 & 13.75 \\
\hline \multicolumn{9}{|l|}{ Sex } \\
\hline Male & 83.08 & 9.92 & 72.63 & 16.76 & 79.19 & 15.63 & 83.07 & 12.99 \\
\hline Female & 83.15 & 10.17 & 75.27 & 15.37 & 80.62 & 14.83 & 83.29 & 12.81 \\
\hline Total & 83.10 & 9.95 & $73.43^{b}$ & 16.33 & 79.62 & 15.34 & 83.14 & 14.89 \\
\hline
\end{tabular}

${ }^{a}$ Significantly higher than high school $(P \leq .05)$.

${ }^{b}$ Significantly lower than baseline $(P \leq .05)$.

TABLE 5

Means and Standard Deviations (SDs) for Visual Memory Performance for Concussed Male and Female High School $(\mathrm{n}=150)$ and Collegiate $(\mathrm{n}=72)$ Athletes

\begin{tabular}{|c|c|c|c|c|c|c|c|c|}
\hline & \multicolumn{2}{|c|}{ Baseline } & \multicolumn{2}{|c|}{2 Days } & \multicolumn{2}{|c|}{7 Days } & \multicolumn{2}{|c|}{14 Days } \\
\hline & Mean & $\mathrm{SD}$ & Mean & $\mathrm{SD}$ & Mean & $\mathrm{SD}$ & Mean & SD \\
\hline \multicolumn{9}{|l|}{ Age group } \\
\hline High school & 71.25 & 14.49 & 60.77 & 16.71 & 63.11 & 15.85 & 70.66 & 16.12 \\
\hline College & 73.54 & 11.43 & $67.18^{a}$ & 13.42 & 67.53 & 19.17 & 68.15 & 15.66 \\
\hline \multicolumn{9}{|l|}{ Sex } \\
\hline Male & 72.38 & 14.12 & 63.51 & 16.22 & 66.13 & 17.43 & 70.93 & 15.71 \\
\hline Female & 71.09 & 12.37 & 61.24 & 15.44 & 60.84 & 15.69 & 67.41 & 15.49 \\
\hline Total & 71.98 & 13.58 & $62.82^{b}$ & 15.96 & $64.52^{b}$ & 17.03 & $69.86^{c, d}$ & 15.66 \\
\hline
\end{tabular}

${ }^{a}$ Significantly higher than high school $(P \leq .05)$.

${ }^{b}$ Significantly lower than baseline $(P \leq .05)$.

${ }^{c}$ Significantly higher than 2 days $(P \leq .05)$.

${ }^{d}$ Significantly higher than 7 days $(P \leq .05)$.

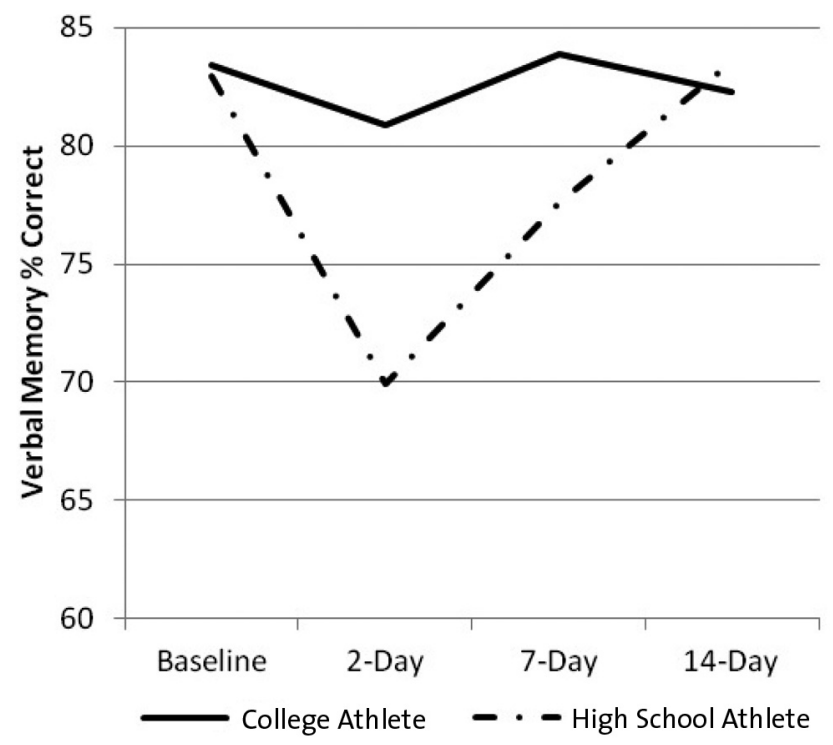

Figure 2. Age $\times$ time interaction for verbal memory.

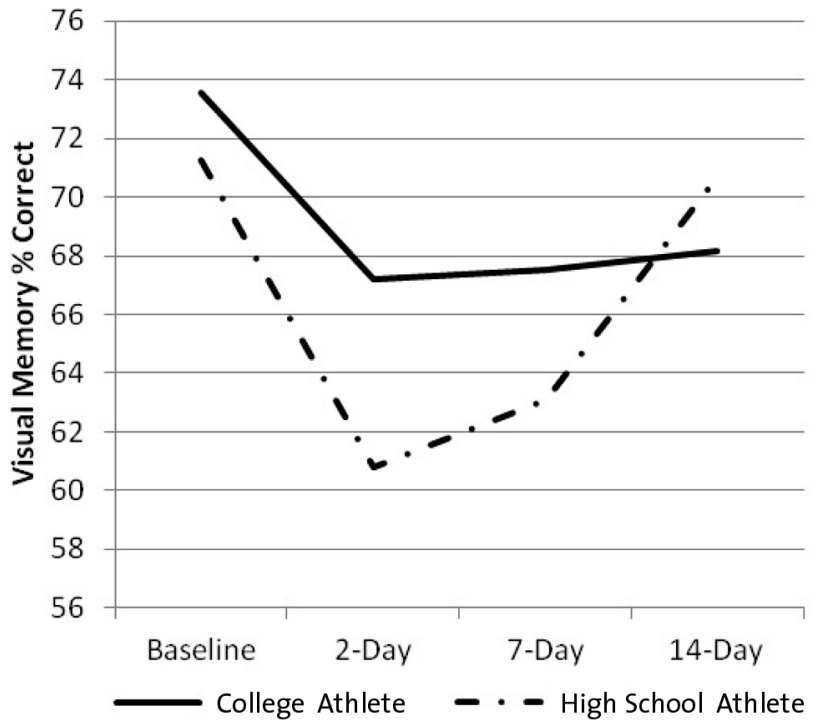

Figure 3. Age $\times$ time interaction for visual memory. 
TABLE 6

Means and Standard Deviations (SDs) for Reaction Time for Concussed Male and Female High School $(n=150)$ and Collegiate $(n=72)$ Athletes

\begin{tabular}{|c|c|c|c|c|c|c|c|c|}
\hline & \multicolumn{2}{|c|}{ Baseline } & \multicolumn{2}{|c|}{2 Days } & \multicolumn{2}{|c|}{7 Days } & \multicolumn{2}{|c|}{14 Days } \\
\hline & Mean & SD & Mean & SD & Mean & SD & Mean & SD \\
\hline \multicolumn{9}{|l|}{ Age group } \\
\hline High school & 0.592 & 0.075 & 0.673 & 0.155 & 0.609 & 0.149 & 0.579 & 0.094 \\
\hline College & 0.584 & 0.067 & 0.648 & 0.155 & 0.594 & 0.176 & 0.578 & 0.131 \\
\hline \multicolumn{9}{|l|}{ Sex } \\
\hline Male & 0.592 & 0.073 & 0.667 & 0.155 & 0.604 & 0.151 & 0.578 & 0.091 \\
\hline Female & 0.583 & 0.071 & 0.661 & 0.157 & 0.621 & 0.227 & 0.583 & 0.137 \\
\hline Total & 0.589 & 0.072 & $0.665^{a}$ & 0.155 & 0.604 & 0.157 & 0.579 & 0.106 \\
\hline
\end{tabular}

${ }^{a}$ Significantly slower than baseline $(P \leq .05)$.

TABLE 7

Means and Standard Deviations (SDs) for Motor Processing Speed for Concussed Male and Female High School $(\mathrm{n}=150)$ and Collegiate $(\mathrm{n}=72)$ Athletes

\begin{tabular}{|c|c|c|c|c|c|c|c|c|}
\hline & \multicolumn{2}{|c|}{ Baseline } & \multicolumn{2}{|c|}{2 Days } & \multicolumn{2}{|c|}{7 Days } & \multicolumn{2}{|c|}{14 Days } \\
\hline & Mean & SD & Mean & SD & Mean & SD & Mean & SD \\
\hline \multicolumn{9}{|l|}{ Age group } \\
\hline High school & 35.43 & 6.68 & 33.18 & 9.63 & 36.55 & 9.4 & 38.16 & 8.48 \\
\hline College & 38.99 & 6.00 & 36.52 & 8.68 & 37.94 & 9.55 & 40.74 & 8.28 \\
\hline \multicolumn{9}{|l|}{ Sex } \\
\hline Male & 35.73 & 6.64 & 33.75 & 9.81 & 36.61 & 9.76 & 38.32 & 8.52 \\
\hline Female & 38.49 & 6.36 & 35.39 & 8.53 & 37.88 & 8.77 & 39.79 & 9.54 \\
\hline Total & 36.57 & 6.65 & 34.25 & 9.43 & 36.99 & 9.45 & $38.99^{a}$ & 8.47 \\
\hline
\end{tabular}

${ }^{a}$ Significantly higher than baseline $(P \leq .05)$.

(Wilks $\lambda=.759, \mathrm{~F}_{3,116}=12.25, P=.001, \eta^{2}=.241$ ). Athletes exhibited slower reaction times at 2 days after concussion $(P=.001)$ but returned to baseline by 7 days after concussion $(P=.75)$. Athletes' motor processing speed scores at 2 days $(P=.16)$ and 7 days $(P=.75)$ after concussion were not significantly $(P=1.00)$ different from baseline. However, at 14 days after concussion, athletes' motor processing speed scores were significantly better than at baseline. There were no significant age differences between high school and collegiate athletes on motor processing speed $\left(\mathrm{F}_{1,118}=1.422, P=.235, \eta^{2}=.012\right)$ or reaction time $\left(\mathrm{F}_{1,117}=.157, P=.693, \eta^{2}=.001\right)$. There were no significant within-subjects interaction for time and age for reaction time (Wilks $\lambda=.99, \mathrm{~F}_{3,115}=.195, P=.90, \eta^{2}=$ .005 ) or motor processing speed (Wilks $\lambda=.98, \mathrm{~F}_{3,116}=$ $\left..953, P=.42, \eta^{2}=.024\right)$. Means and standard deviations for reaction time and motor processing speed can be found in Tables 6 and 7, respectively.

\section{Neurocognitive Performance and Sex Differences}

We performed a series of $2($ sex $) \times 2$ (age) $\times 4$ (time) RM ANOVAs for each ImPACT composite score. Results revealed a between-groups main effect for sex on visual memory $\left(\mathrm{F}_{1,118}=3.95, P=.049, \eta^{2}=.032\right)$, with female athletes performing worse than male athletes. The results did not support sex differences for verbal memory $\left(\mathrm{F}_{1,118}=\right.$ .102, $P=.750, \eta^{2}=.001$ ), motor processing speed $\left(\mathrm{F}_{1,118}=1.291, P=.258, \eta^{2}=.011\right)$, or reaction time $\left(\mathrm{F}_{1,118}=.098, P=.755, \eta^{2}=.001\right)$.

When we examined the interaction between sex and age, there were no significant interactions for visual memory $\left(\mathrm{F}_{1,118}=1.29, P=.258, \eta^{2}=.011\right)$, verbal memory $\left(\mathrm{F}_{1,118}=.682, P=.411, \eta^{2}=.006\right)$, motor processing speed $\left(\mathrm{F}_{1,118}=2.41, P=.123, \eta^{2}=.02\right)$, or reaction time $\left(\mathrm{F}_{1,118}=\right.$ 1.253, $P=.265, \eta^{2}=.011$ ).

\section{DISCUSSION}

The findings from the current study suggest that concussed high school and collegiate athletes exhibit different outcomes after concussion. Specifically, high school concussed athletes performed worse than college concussed athletes on verbal and visual memory. With regard to sex, female athletes performed worse than male athletes on visual memory and reported more postinjury symptoms after concussion. Finally, results of this study also supported an interaction between sex and age on the BESS, 
with high school male athletes demonstrating worse overall performance than college male athletes, and college female athletes demonstrating worse overall performance on the BESS than high school female athletes.

The different recovery times for concussed high school and collegiate athletes in the present study are in accordance with previous research that has suggested that high school athletes take longer to recover from concussion than do collegiate athletes. ${ }^{15,19,24,31}$ Prolonged decrements in memory performance have been reported in high school athletes at 10 days $^{24}$ and 14 days after concussion. ${ }^{31}$ Moreover, a recent study by Covassin et al $^{9}$ reported memory impairment lasting up to 14 days after injury in a sample of concussed high school athletes. Although the present study did not report any age differences for recovery time on motor processing speed or reaction time, previous researchers have documented persistent impairments for reaction time up to 21 days and up to 14 days after concussion for motor processing speed in high school athletes. ${ }^{9}$ Differences in the present study and the previous study by Covassin and colleagues ${ }^{9}$ may be caused by differences in research design. Covassin and colleagues ${ }^{9}$ only utilized high school athletes, while this study compared high school athletes and collegiate athletes. Overall, results of this study and other studies suggest that, on average, neurocognitive impairments may persist from 10 to 21 days after concussion for high school athletes, which is longer than the 5- to 7-day neurocognitive recovery documented in collegiate samples.

To date, there have been few studies that have reported sex differences among high school and collegiate athletes who have incurred a sport-related concussion. The results of the current study indicated that female athletes reported more concussion symptoms than male athletes. This finding supported the findings of Broshek and colleagues ${ }^{5}$ and Colvin and colleagues, ${ }^{7}$ who also reported that female athletes exhibit more total concussion symptoms than male athletes. Researchers have suggested that male athletes play through pain and try to hide and minimize their symptoms in an effort to avoid removal from sport, whereas female athletes tend to be more concerned about their future health. ${ }^{20}$ In addition, male athletes may lack awareness of or choose to ignore their concussion symptoms after injury.

In addition to sex differences on symptoms, female athletes also exhibited worse visual memory scores than male athletes after a concussion. These results support previous literature that has reported that female athletes performed worse on visual memory than male athletes. ${ }^{10}$ Interestingly, in the current study, male and female athletes demonstrated similar performance for reaction time, which was in contrast to previous findings. ${ }^{5,7}$ Nonetheless, there appears to be consistency in more recent literature that highlights sex differences in visual memory in sportrelated concussion outcomes.

Future research needs to investigate if reported sex differences are caused by female sex hormones (ie, estrogen), ${ }^{26,37}$ cerebral blood flow rate, ${ }^{18}$ basal rate of glucose metabolism, ${ }^{1}$ or other factors. Researchers have investigated the role of female gonadal hormones in traumatic brain injury (TBI) in animal models and reported that estrogen may act as a neuroprotective mechanism after TBI because of its hormone's lipid antioxidant properties. ${ }^{14,23}$ Further, progesterone may also have a neuroprotective effect as Djebali and colleagues ${ }^{14}$ suggested. Specifically, progesterone may decrease cerebral edema and potentially downregulate the inflammatory response to TBI. However, in contrast to the aforementioned research, Emerson and colleagues ${ }^{17}$ administered estrogen to rats before inducing a fluid percussion brain injury and reported that estrogen exacerbated the injury in female rats but served as a protective factor in male rats. It is important to note that these studies focused on TBI rather than concussion. Further research is warranted on humans to determine the role that female sex hormones play on the recovery from brain injury and in particular milder forms of brain injury such as concussion.

Several researchers have suggested that women may have a greater rate of cerebral blood flow ${ }^{18}$ and basal rate of glucose metabolism. ${ }^{1}$ Broshek and colleagues ${ }^{5}$ suggest that as a result of women's increased demands for glucose and cerebral blood flow, a concussion may exacerbate the neurometabolic cascade after injury, resulting in further decreases in cerebral blood flow and increases in glycemic demands. Consequently, concussed female athletes may exhibit prolonged neurocognitive impairments compared with male athletes.

The findings from the study suggested that the BESS was somewhat effective in assessing acute changes in postural stability after a concussion. The BESS scores were lower at 1 day after injury than at 2 and 3 days after injury. Without a baseline score, it is difficult to determine if athletes were impaired on the BESS at 3 days after injury on postural stability. Similarly, without a follow-up BESS score beyond 3 days, it is difficult to determine if athletes were normalized. However, several researchers suggest the use of postural stability measures such as the BESS should occur only in the first few days (ie, up to 3 days) after concussion to provide initial evaluation of concussion. $^{22,35,36}$ Interestingly, there was a between-subjects interaction for sex and age on the BESS, with high school male athletes demonstrating worse overall performance than male college athletes, and college female athletes demonstrated worse overall performance on the BESS than female high school athletes. These between-subjects differences in the BESS suggest that age and sex should be considered when interpreting the results of the BESS and other postural stability tests following concussion.

Neurocognitive data from the present study further support the use of serial NCT as one valuable tool in a comprehensive assessment and management approach to concussion. In the current sample, there were significant NCT performance declines from baseline to after concussion. Specifically, athletes exhibited significant decreases in NCT performance from baseline to 2 days (verbal and visual memory, reaction time) and 7 days (visual memory) after concussion. However, by 14 days after concussion, NCT scores were no longer significantly different from 
baseline levels. Not surprisingly, there was an overall trend among postconcussion neurocognitive data, indicating lower performance for high school athletes compared with older college athletes. These data support current management recommendations ${ }^{33}$ that call for a conservative approach when making return-to-play decisions among adolescent athletes.

\section{Limitations}

In the current study, the researchers assumed that participants were honest when completing the self-report concussion symptom scale. In addition, there is no gold standard for measuring symptoms to compare results, and each concussion may vary, making comparisons across all concussions difficult.

It was also assumed that participants completed with full effort the NCT and postural stability assessments, particularly at baseline. The measures in the current study were assumed to be both valid and reliable based on previously published data. The current study was limited by several factors including age (high school and college) and sport (sport vs nonsport). Consequently, the results of the current study cannot be generalized to youth under age 14 years or adults over age 30 years or nonsport participants.

\section{CONCLUSION}

The results of the current study supported age differences in memory, sex differences in memory and symptoms, and interaction between age and sex on postural stability after concussion that warrant consideration from clinicians and researchers when interpreting symptoms, specific components of NCT, and postural stability tests. The results of the current study suggest that age and sex should be considered when interpreting the results of symptom reports, $\mathrm{NCT}$, and postural instability assessments following concussion. Among the strengths of the current study were the large sample size, prospective pretest-posttest design, combination of multiple methods of measurements (ie, symptoms, NCT, postural stability), and inclusion of high school and college athletes as well as male and female athletes. The researchers believe that the methods and findings from the current study set a strong initial foundation from which future research efforts, including intervention studies tailored to age and sex differences, can be conducted. Future studies should also include youth $(<13$ years) sport participants to determine if sex and age differences extend to these populations.

\section{ACKNOWLEDGMENT}

We thank the National Operating Committee on Standards for Athletic Equipment (NOCSAE) for funding this study. We also thank all the certified athletic trainers for their contributions to this study.

\section{REFERENCES}

1. Andreason P, Zametkin A, Guo A, Baldwin P, Cohen R. Genderrelated differences in regional cerebral glucose metabolism in normal volunteers. Psychiatry Res. 1994;51:175-183.

2. Aubry M, Cantu R, Dvorak J, et al. Summary and agreement statement of the 1st International Symposium on Concussion in Sport, Vienna 2001. Clin J Sport Med. 2002;12(1):6-11.

3. Bakhos LL, Lockhart GR, Myers R, Linakis JG. Emergency department visits for concussion in young child athletes. Pediatrics. 2010;126(3):e550-e556.

4. Boden B, Kirkendall D, Garrett WE Jr. Concussion incidence in elite college soccer players. Am J Sports Med. 1998;26(2):238-241.

5. Broshek DK, Kaushik T, Freeman JR, Erlanger D, Webbe F, Barth JT. Sex differences in outcome following sports-related concussion. J Neurosurg. 2005;102(5):856-863.

6. Cantu RC, Guskiewicz K, Register-Mihalik JK. A retrospective clinical analysis of moderate to severe athletic concussions. PM $R$. 2010;2(12):1088-1093.

7. Colvin A, Mullen J, Lovell M, West RV, Collins MW, Groh M. The role of concussion history and gender in recovery from soccer-related concussion. Am J Sports Med. 2009;37(9):1699-1704.

8. Covassin T, Elbin R, Kontos A, Larson E. Investigating baseline neurocognitive performance between male and female athletes with a history of multiple concussion. J Neurol Neurosurg Psychiatry. 2010;81(6):597-601.

9. Covassin T, Elbin R, Nakayama Y. Tracking neurocognitive performance following concussion in high school athletes. Phys Sportsmed. 2010;38(4):87-93.

10. Covassin T, Schatz P, Swanik CB. Sex differences in neuropsychological function and post-concussion symptoms of concussed collegiate athletes. Neurosurgery. 2007;61:345-351.

11. Covassin T, Swanik CB, Sachs ML. Sex differences and the incidence of concussions among collegiate athletes. J Athl Train. 2003;38(3):238-244.

12. Covassin T, Swanik CB, Sachs M, et al. Sex differences in baseline neuropsychological function and concussion symptoms of collegiate athletes. Br J Sports Med. 2006;40(11):923-927, discussion 927.

13. de Courten-Myers GM. The human cerebral cortex: gender differences in structure and function. J Neuropathol Exp Neurol. 1999;58:217-226.

14. Djebaili M, Guo Q, Pettus E, Hoffman S, Stein D. The neurosteroids progesterone and allopregnanolone reduce cell death, gliosis, and functional deficits after traumatic brain injury in rats. J Neurotrauma. 2005;22:106-118.

15. Echemendia RJ, Putukian M, Mackin RS, Julian L, Shoss N. Neuropsychological test performance prior to and following sports-related mild traumatic brain injury. Clin J Sport Med. 2011;11(1):23-31.

16. Elbin RJ, Schatz P, Covassin T. One-year test-retest reliability of the online version of ImPACT in high school athletes. Am J Sports Med. 2011;39(11):2319-2324.

17. Emerson CS, Headrick JP, Vink R. Estrogen improves biochemical and neurologic outcome following traumatic brain injury in male rats, but not females. Brain Res. 1993;608:95-100.

18. Esposito G, Van Horn JD, Weinberger DR, Berman KF. Gender differences with cerebral blood flow as a function of cognitive state with PET. J Nucl Med. 1996;37:559-564.

19. Field M, Collins MW, Lovell MR, Maroon J. Does age play a role in recovery from sports-related concussion? A comparison of high school and collegiate athletes. J Pediatr. 2003;142:546-553.

20. Granite V, Carroll J. Psychological response to athletic injury: sex differences. J Sport Behavior. 2002;25:243-259.

21. Guskiewicz KM, Bruce SL, Cantu RC, et al. Research based recommendations on management of sport related concussion: summary of the National Athletic Trainers' Association position statement. Br J Sports Med. 2006;40(1):6-10.

22. Guskiewicz KM, Ross SE, Marshall SW. Postural stability and neuropsychological deficits after concussion in collegiate athletes. J Athl Train. 2001;36(3):263-273. 
23. Hall ED, Pazara KE, Linseman KL. Sex differences in postischemic neuronal necrosis in gerbils. J Cereb Blood Flow Metab. 1991;11:292-298.

24. Iverson GL, Brooks BL, Collins MW, Lovell MR. Tracking neuropsychological recovery following concussion in sport. Brain Inj. 2006;20(3):245-252.

25. Kimura D, Clarke PG. Women's advantage on verbal memory is not restricted to concrete words. Psychol Rep. 2002;91:1137-1142.

26. Kupina NC, Detloff MR, Bobrowski WF, Snyder BJ, Hall ED. Cytoskeletal protein degradation and neurodegeneration evoles differently in males and females following experimental head injury. Exp Neurol. 2003;180:55-73.

27. Langlois JA, Rutland-Brown W, Wald MM. The epidemiology and impact of traumatic brain injury: a brief overview. J Head Trauma Rehabil. 2006;21(5):375-378.

28. Lee AJ, Lin WH. The influence of gender and somatotype on singleleg upright standing postural stability in children. $J$ Appl Biomech. 2007;23(3):173-179.

29. Lovell MR, Iverson GL, Collins MW, et al. Measurement of symptoms following sports-related concussion: reliability and normative data for the post-concussion scale. Appl Neuropsychol. 2006;13:166-174.

30. Macciocchi SN, Barth JT, Alves W, Rimel RW, Jane JA. Neuropsychological functioning and recovery after mild head injury in collegiate athletes. Neurosurgery. 1996;39(3):510-514.

31. McClincy MP, Lovell MR, Pardini J, Collins MW, Spore MK. Recovery from sports concussion in high school and collegiate athletes. Brain Inj. 2006;20(1):33-39.

32. McCrory P, Collie A, Anderson V, Davis G. Can we manage sport related concussion in children the same as in adults? $\mathrm{Br} J$ Sports Med. 2004;38(5):516-519.

33. McCrory P, Meeuwisse W, Johnston K, et al. Consensus statement on concussion in sport: the 3rd International Conference on
Concussion in Sport held in Zurich, November 2008. Br J Sports Med. 2009;43(Suppl 1):i76-i90.

34. Moser RS, Schatz P, Jordan BD. Prolonged effects of concussion in high school athletes. Neurosurgery. 2005;57(2):300-306.

35. Riemann BL, Guskiewicz KM. Effects of mild head injury on postural stability as measured through clinical balance testing. J Athl Train. 2000;35:19-25.

36. Riemann BL, Guskiewicz KM, Shields EW. Relationship between clinical and forceplate measures of postural stability. J Sport Rehabil. 1999;8(2):71-82.

37. Roof RL, Hall ED. Gender differences in acute CNS trauma and stroke: neuroprotective effects of estrogen and progesterone. J Neurotrauma. 2000;17:367-388.

38. Schatz P. Long-term test-retest reliability of baseline cognitive assessments using ImPACT. Am J Sports Med. 2010;38(1):47-53.

39. Schatz P, Pardini J, Lovell MR, Collins MW, Podell K. Sensitivity and specificity of the ImPACT test battery for concussion in athletes. Arch Clin Neuropsychol. 2006;21:91-99.

40. Shehata N, Wiley JP, Richea S, Benson BW, Duits L, Meeuwisse WH. Sport concussion assessment tool: baseline values for varsity collision sport athletes. Br J Sports Med. 2009;43:730-734.

41. Tierney RT, Higgins M, Caswell SV, et al. Sex differences in head acceleration during heading while wearing soccer headgear. J Athl Train. 2008;43(6):578-584.

42. Tierney RT, Sitler MR, Swanik CB, Swanik KA, Higgins M, Torg J. Gender differences in head-neck segment dynamic stabilization during head acceleration. Med Sci Sports Exerc. 2005;37: 272-279.

43. Van Kampen DA, Lovell MR, Pardini JE, Collins MW, Fu FH. The "value added" of neurocognitive testing after sports-related concussion. Am J Sports Med. 2006;34(10):1630-1635. 